\title{
Parental origin of triploidy and D and G trisomy in spontaneous abortions
}

\author{
B. G. BRENNAN AND D. H. CARR \\ From the Department of Anatomy, McMaster University Medical Centre, Hamilton, Ontario, Canada
}

\begin{abstract}
SUMmARY A cytogenetic study of 15 triploid spontaneous abortuses, 12 trisomic abortuses, and their parents was carried out using the Q-banding technique. Polymorphic regions in abortus chromosomes were compared to corresponding regions of parental chromosomes to determine the origin of the extra chromosomes. Using marker chromosomes it was found that 7 triploids and only one trisomy were informative. Three triploids arose by failure to shed the second polar body during oogenesis. One triploid arose by dispermy. The other three triploids inherited an extra haploid set of chromosomes from the father, either by dispermy or by failure of the second meiotic division during spermatogenesis. The only informative trisomy, a trisomy 22 , inherited the extra 22 from the mother. Chromosome polymorphisms are useful in determining the parental origin of extra chromosomes in certain cases.
\end{abstract}

In 1970 it was found that quinacrine, a fluorescent dye, produced a characteristic banding pattern on each chromosome pair of the human complement (Caspersson et al., 1970). Specific chromosomal regions are polymorphic when quinacrine is used, and these polymorphisms are inherited in a Mendelian manner (Robinson et al., 1976). These variant regions provide a method for distinguishing between homologous pairs. Using fluorescent marker chromosomes, the inheritance of the extra chromosomes found in triploids and trisomies could be studied. Triploids and trisomies represent approximately $60 \%$ of spontaneous abortions with an abnormal karyotype.

Trisomies arise by non-disjunction either during the first or second meiotic division in oogenesis, or during spermatogenesis. Triploids result from one of three possible events: fertilisation of a diploid ovum by a haploid sperm, fertilisation of a haploid ovum by a diploid sperm, or fertilisation by two sperms. The former type is called digyny and the latter two diandry. These events can be differentiated sometimes by using chromosome markers. In certain triploids the sex chromosome complement may give additional information. For example, if the triploid were $\mathrm{XXY}$ and marker studies identified the extra chromosomes as being from the father, this triploid would have resulted from failure of the second meiotic division in spermatogenesis resulting in an Received for publication 21 November 1978
XY diploid sperm, or from fertilisation with two sperms, one $\mathrm{X}$ and one $\mathrm{Y}$.

We sought to determine, whenever possible, the origin of the extra chromosomes found in triploid and $D$ and $G$ trisomic spontaneous abortions.

\section{Materials and methods}

The spontaneous abortuses used in this study were part of a larger series collected from 1972 to 1977. The abortuses were received from the Henderson General Hospital, St. Joseph's Hospital, and the McMaster University Medical Centre, all in Hamilton, Ontario.

Tissue from the chorion of the abortuses was cultured and karyotyped by $\mathbf{M}$. Gedeon. The parents of 15 triploid abortuses and $12 \mathrm{D}$ and $\mathrm{G}$ trisomic abortuses were contacted and arrangements made to obtain a venous blood sample. Lymphocytes were cultured according to the method previously described in detail (Carr, 1975).

Slides were stained with quinacrine dihydrochloride and observed with fluorescent photomicroscopy. Parents were karyotyped to ensure normality. Quinacrine polymorphisms in the abortus chromosomes were compared with those in the parental chromosomes. The fluorescent intensity levels suggested in the Paris Conference Supplement (1975) were not used. Instead, three levels were used as criteria: absent fluorescence, fluorescence present 
but not brilliant, and brilliant fluorescence. This was believed to be more clear-cut than the five-level scale.

\section{Results}

The chromosomes of the parents of all abortuses were normal by the Q-banding technique. Of the 15 triploids examined, 7 were informative as to the origin of the extra set of chromosomes. In 3 of these cases, the second polar body failed to extrude during oogenesis (Fig. a, b, c). In these triploids, 2 of the marker chromosomes are from the mother and are identical, indicating that the failure to separate must have occurred at the second meiotic division. In 3 other triploids it was impossible to distinguish between failure of the second meiotic division during spermatogenesis and fertilisation by two sperms (Fig. d, e, f). In a fourth diandric triploid, the sex chromosome complement $(69, \mathrm{XXY})$ ruled out failure of the second meiotic division; therefore, this triploid arose by dispermy (Fig. g).

No chromosome marker was consistently of value in determining the origin of the extra haploid set of chromosomes. Chromosomes 4,13,14, 15, and $\underset{\mathbb{T}}{\stackrel{\Phi}{1}}$ were used.

Only one of the 12 trisomies examined was formative. This was a trisomy 22 in which the exfra 22 was from the mother. It was not possible fo distinguish between non-disjunction during meioms I and meiosis II.

\section{Discussion}

Several authors have examined the origin of extra chromosomes, both in liveborn and spontaneousty aborted triploids and trisomies. With respect to origin of Down's syndrome, studies have shown that approximately $30 \%$ of cases arose by non-disjunction in the father (Langenbeck et al., 1976), and that, the whole, non-disjunction in meiosis I was 5 to 10 times more common than in meiosis II. Reports the origin of pure triploidy are numerous (reviewed by Lauritsen, 1976; Kajii and Niikawa, 1977).

We found that 7 of 15 triploids were informative, compared to one of 12 trisomies. The greater number of informative triploids compared to autosonatal trisomies is because more chromosome pairs âte

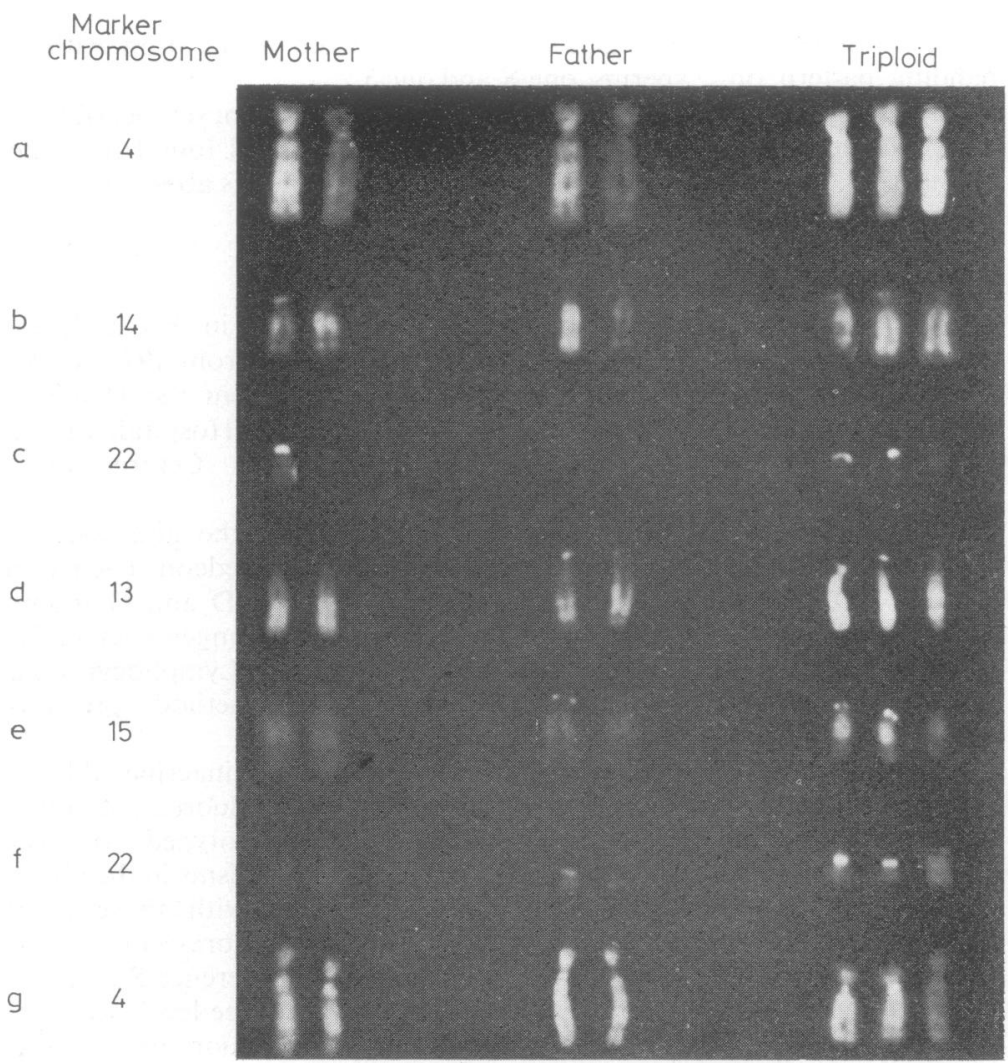

Fig. Marker chromosomes of parents and their triploid abortuses in the 7 informative $\mathrm{O}$ cases. 
available for study; hence, there is a greater chance of finding a useful chromosome marker in triploidy.

One proposed cause of chromosome anomalies is the aging of gametes. Aging of oocytes may be intrafollicular (delayed ovulation) or intratubal (delayed fertilisation), and aging of sperm may occur in either the male or female reproductive tract. In this study the three digynic triploids resulted from failure to shed the second polar body. In a number of animal species, delayed fertilisation causes retention of the second polar body (Braden and Austin, 1954). In rats (Fugo and Butcher, 1966) and frogs (Mikamo, 1968), delays in ovulation cause an increase in triploid embryos which is mainly the result of dispermy. A delay between ovulation and fertilisation has been reported to cause a similar phenomenon in rabbits (Shaver and Carr, 1967) and mice (Vickers, 1969). Animal studies suggest that diploid sperm may not be an important cause of triploidy (Fechheimer and Beatty, 1974).

Human data are sparse concerning the effects of aging of gametes. If the animal data can be generalised to humans, then dispermy and retention of the second polar body are the most common causes of triploidy. Since the incidence of triploidy does not increase with advanced maternal age, the aging of the ovum which is responsible for the production of a triploid zygote is probably postovulatory overripeness.

Using the criteria applied in the present study, we found that the parental origin of those triploids cited by McConnell and Carr (1975) cannot be determined.

Intrafollicular overripeness is one of the possible mechanisms for the production of $\mathrm{D}$ and $\mathrm{G}$ trisomies. This is compatible with the finding that advanced maternal age is associated with an increased incidence of $D$ and $G$ trisomies, whether liveborn or aborted spontaneously (Boué et al., 1975). Other possible aetiological factors may account for those trisomies which are not related to late maternal age, and those in which the extra chromosome is from the father. One of the best studied factors is maternal irradiation, first proposed by Uchida and Curtis (1961). Other theories of non-disjunction include thyroid antibodies (Fialkow et al., 1965), endocrinological factors (Janerich and Jacobson, 1977), and virus infection (Evans, 1967).

The development of additional chromosome staining techniques to increase the number of polymorphic features will enable more detailed information on the origin of extra chromosomes to be obtained. This will facilitate the study of the effects of various environmental factors on chromosome behaviour during oogenesis and spermatogenesis.

The technical assistance of M. Gedeon is gratefully acknowledged. This research was supported by grants from the Medical Research Council of Canada and the J. P. Bickell Foundation.

\section{References}

Boué, J., Boué, A., and Lazar, P. (1975). Retrospective and prospective epidemiological studies of 1500 karyotyped spontaneous abortions. Teratology, 12, 11-26.

Braden, A. W. H., and Austin, C. R. (1954). Fertilization of the mouse egg and the effect of delayed coitus and of hotshock treatment. Australian Journal of Biological Science, 7, 552-556.

Carr, D. H. (1975). Cytogenetics and the pathologists. Pathology Annual, 10, 93-144.

Caspersson, T., Zech, L., and Johansson, C. (1970). Differential binding of alkylating fluorochromes in human chromosomes. Experimental Cell Research, 60, 315-319.

Evans, H. J. (1967). The nucleolus, virus infection and trisomy in man. Nature, 214, 361-363.

Fechheimer, N. S., and Beatty, R. A. (1974). Chromosomal abnormalities and sex ratio in rabbit blastocysts. Journal of Reproduction and Fertility, 37, 331-341.

Fialkow, P. J., Hecht, F., Uchida, I. A., and Motulsky, A. G. (1965). Increased frequency of thyroid auto-antibodies in mothers of patients with Down's syndrome. Lancet, 2, 868-870.

Fugo, N. W., and Butcher, R. L. (1966). Overripeness and the mammalian ova. Fertility and Sterility, 17, 804-814.

Janerich, D. T., and Jacobson, H. I. (1977). Seasonality in Down syndrome. Lancet, 1, 515-516.

Kajii, T., and Niikawa, N. (1977). Origin of triploidy and tetraploidy in man: 11 cases with chromosome markers. Cytogenetics and Cell Genetics, 18, 109-125.

Langenbeck, V., Hansmann, I., Hinney, B., and Honig, V. (1976). On the origin of the supernumerary chromosome in autosomal trisomies - with special reference to Down's syndrome. Human Genetics, 33, 89-102.

Lauritsen, J. G. (1976). Aetiology of spontaneous abortion: a cytogenetic and epidemiological study of 288 abortuses and their parents. Acta Obstetricia et Gynecologica Scandinavica. Suppl. 52.

McConnell, H. D., and Carr, D. H. (1975). Recent advances in the cytogenetic study of human spontaneous abortions. Obstetrics and Gynecology, 45, 547-552.

Mikamo, K. (1968). Intrafollicular overripeness and teratologic development. Cytogenetics, 7, 212-233.

Paris Conference Supplement (1975). Standardization in human cytogenetics. Birth Defects: Original Article Series, 11, No. 9. The National Foundation-March of Dimes, New York.

Robinson, J. A., Buckton, K. E., Spowart, G., Newton, M., Jacobs, P. A., Evans, H. J., and Hill, R. (1976). The segregation of human chromosome polymorphisms. Annals of Human Genetics, 40, 113-121.

Shaver, E. L., and Carr, D. H. (1967). Chromosome abnormalities in rabbit blastocysts following delayed fertilization. Journal of Reproduction and Fertility, 14, 415-420.

Uchida, I. A., and Curtis, E. J., (1961). A possible association between maternal radiation and mongolism. Lancet, 1, 848-850.

Vickers, A. D. (1969). Delayed fertilization and chromosomal anomalies in mouse embryos. Journal of Reproduction and Fertility, 20, 69-76.

Requests for reprints to Dr D. H. Carr, Department of Anatomy, McMaster University Medical Centre, Hamilton, Ontario, Canada. 